\section{Judicialização das políticas públicas e inefetividade dos direitos sociais na Constituição Federal de 1988}

\author{
JUdicialization OF PUBLIC POLITICS AND \\ INEFFECTIVENESS OF SOCIAL RIGHT AT THE \\ Federal Constitution of 1988
}

\author{
* Marlene Kempfer \\ ** Rafael Zambon de Moraes
}

Resumo: O Estado Democrático de Direito que a Constituição Federal de 1988 visa construir tem por fundamento os ideais do Estado de Direito e do Estado Social. A contribuição do primeiro, essencialmente, é estabelecer limites ao poder do Estado, estruturando suas funções de acordo com a ideia da tripartição de poderes de Montesquieu, garantir a liberdade individual e a propriedade privada. Predomina a função legislativa, a primeira dimensão de direitos fundamentais e um ordenamento jurídico estático, dentro do qual a jurisdição busca soluções. O Estado Social, por sua vez, proclama os direitos de segunda dimensão em que o Estado, por meio do Executivo, atua com os olhos voltados às prestações de caráter positivo. O Judiciário, neste momento, quando provocado para fazer concretizar os direitos sociais, interfere nas funções executivas, possibilitando o estudo da judicialização das políticas públicas. O enfoque desta pesquisa considera os argumentos apresentados, dirigindo-os ao direito social e o problema de sua efetividade em face da disponibilidade financeira do Estado (a reserva do possível).

Palavras-chave: Judicialização; Reserva do Possível; Direitos Sociais; Efetividade.

Abstract: The Democratic State under the Rule of Law that the Federal Constitution of 1988 seeks to build is based on notions which are related to the liberal State of Law and to the Welfare State. The contribution of the first is to establish limits to the power of the State, structuring its functions according to the classic idea of the tripartition of powers of Montesquieu, and providing freedom to the individual. Predominates, here, the legislative function. There is, in this moment, the so-called first dimension of the fundamental rights and a statical order, from which the jurisdictional activity searchs for all kinds of solutions. On the other hand, the Welfare State proclaims the second dimension rights, in which the State acts with his eyes turned to 
measures of positive character. The Judiciary, when provoked, interferes in the executive functions of the State to fulfill the social rights, With this, the study of the judicialization of the public politics turns possible. This work considers the presented arguments and directs it to the social rights and to its effectiveness problem due to the financial disponibility of the State (the Reserve of the Possible).

Keywords: Judicialization; Reserve of the possible; Social Rights; Effectiveness. 


\section{INTRODUÇÃO}

A Constituição Federal de 1988 prevê entre os objetivos fundamentais da república brasileira a promoção do bem-estar de todos por meio dos direitos individuais, sociais, econômicos e culturais. Estas competências são responsabilidades dos órgãos do Estado, os quais, nos termos propostos por Montesquieu, são o Legislativo, o Executivo e o Judiciário.

À época do idealizador da teoria, a separação tinha condão específico de limitar a atuação do Estado, de forma a ser permitido ao cidadão que se fizesse tudo aquilo o que não proibido: exigia-se do governante que não interviesse no campo de liberdade e propriedade do indivíduo. A este primeiro momento atribuise o mérito do reconhecimento dos Direitos Fundamentais de Primeira Dimensão. Ao Legislativo incumbia a preponderante atividade de legislar, restando ao Judiciário apenas a aplicação destas leis ao caso concreto: era ele a "boca da lei".

Segue o momento dos Direitos Fundamentais de Segunda Dimensão, que ocupam espaço e exigem do Estado prestação positiva. Com esta mudança, os órgãos estatais, em especial o Judiciário, deixam seu posto de neutralidade em favor da efetividade de direitos constitucionais que compõem políticas públicas de proteção de um mínimo existencial à vida do cidadão, a exemplo dos direitos à saúde e educação públicas. A esta atuação do judiciário que deixa de ser neutro, dá-se o nome de Judicialização das Políticas Públicas.

A condição de realidade enfrentada pelo administrador público muitas vezes obsta o cumprimento fiel, pleno e imediato dos comandos constitucionais que determinam a concretização dos direitos sociais que compõem essa dimensão de direitos que tanto se alia a um ideal de justiça apaziguador de relevantes contingências sociais. Isto é: a escassez de recursos impede a implementação de políticas públicas da maneira mais desejável, deixando direitos tão raros à existência humana coletiva em situação de incompletude - a norma não se efetiva.

Uma vez que essa norma não efetivada é submetida, em casos concretos, à apreciação do Poder Judiciário, surge a discussão quanto à sua eficácia e aplicabilidade. A discussão sobre a efetivação de normas de direito fundamental social é feita em verdadeiro ambiente de judicialização.

O presente trabalho buscará entender, a partir da leitura da doutrina nacional, a eficácia jurídica e a aplicabilidade da norma constitucional de direito social, para, então, focar a questão da eficácia social (efetividade). Para tanto, 
será feita uma análise do papel do Poder Judiciário no Estado Democrático de Direito defendido pela Constituição Federal de 1988.

Serão percorridas as temáticas da judicialização na relação entre a evolução dos Estados de Direito, Social e Democrático de Direito e os direitos fundamentais, e sua influência na Teoria da Separação dos Poderes; das figuras da judicialização e do ativismo, bem como dos questionamentos e limites que as envolvem; das classificações das normas constitucionais quanto à eficácia; e, por fim, do ponto central do trabalho: o verdadeiro problema para a concretização da norma de direito fundamental social, que envolve a escassez de recursos.

\section{O ESTADO DEMOCRÁTICO DE DIREITO, AS DIMENSÕES DE DIREITOS FUNDAMENTAIS E A SEPARAÇÃO DOS PODERES: FUNDAMENTO À JUDICIALIZAÇÃO DAS POLÍTICAS PÚBLICAS}

A Constituição Federal de 1988 (CF/88), em seu Art. $1^{\circ}$, registra a decisão da Assembléia Nacional Constituinte de que o Brasil quer viver as conquistas de um Estado Democrático de Direito, por meio da estrutura da tripartição dos poderes. Assim, no exercício das funções típicas e atípicas o Legislativo, Executivo e Judiciário devem trabalhar em coordenação e harmonia, para satisfazer as expectativas do povo brasileiro.

O exercício do poder político, nos termos do Art. $1^{\circ}$, parágrafo único da Constituição, far-se-á por meio de representantes eleitos ou até mesmo diretamente. Esta opção é fundamental para afirmar que a soberania sobre as decisões quanto às prioridades das políticas públicas deve ser respeitada e realizada.

Avaliando os dizeres constitucionais, é possível indicar que as competências atribuídas ao atual Estado, em seu aspecto social e econômico, são as defendidas pelos teóricos do Estado Social. Portanto, os governos devem atuar em prol da efetividade dos direitos sociais e transindividuais, uma vez que os direitos individuais podem ser considerados etapa relativamente vencida no Brasil.

Os desafios para avançar na efetividade dos direitos do Art. $6^{\circ}$ da $\mathrm{CF} /$ 88, na atualidade, exigem enfrentar discussões, entre elas, sobre o fenômeno da judicialização destas políticas públicas. A atuação no sentido de promover a efetividade de direitos constitucionais promove uma forte aproximação do 
cidadão e da função jurisdicional. É a esperança de que este percurso direcione as decisões políticas para realizar os objetivos e fundamentos da República Federativa do Brasil.

Para tanto, é importante percorrer uma trajetória de estudos sobre o Estado Democrático de Direito, explicando sua relação com o Estado de Direito e o Estado Social, para a evolução dos direitos fundamentais, com o objetivo de associar à evolução dos Estados de Direito e Social.

\subsection{Estado de Direito e Estado Social}

Com o fim da Revolução Francesa de 1789, o Estado francês deixa de atuar movido por ideais revolucionários de mudança social e passa a buscar o firmamento de certo grau de estabilidade de seus órgãos de poder. Nesse momento, "a ideologia da mudança revolucionária é seguida pela ideologia da estabilização" (VILANOVA, 2003, p. 482), havendo profundos reflexos disso na estrutura do ordenamento jurídico vigente à época, bem como ao enfoque dado aos direitos fundamentais. Passa-se a dar maior importância à limitação do poder estatal - anteriormente absoluto - e buscase a proteção de direitos e garantias individuais de igualdade e liberdade a todos. Está vivo o chamado Estado de Direito liberal.

É marca deste primeiro modelo um mínimo de Estado, que permite o livre desenvolvimento social e econômico. Estatuem-se as leis e estas têm o objetivo básico de conservar a perfeita liberdade do indivíduo. $\mathrm{O}$ abuso do poder é abominado e os mecanismos de controle deste tornam-se mais rígidos. Surge, fortemente, o ideal da Separação dos Poderes, no qual se infla a função legislativa: ela é o melhor modo de representação democrática do povo.

É daí que surge o dizer de José Afonso da Silva (2013, p. 115), que aponta como características do Estado de Direito:

(a) Submissão ao império da lei, que era a nota primária de seu conceito, sendo a lei considerada como ato emanado formalmente do Poder Legislativo, composto de representantes do povo, mas do povo-cidadão; (b) divisão de poderes, que separe de forma independente e harmônica os poderes legislativo, executivo e Judiciário, como técnica que assegure a produção das leis ao primeiro e a independência e imparcialidade do último em face dos demais e das pressões dos poderosos particulares; (c) enunciado e garantia dos direitos individuais. 
O momento de estabilidade seguido à Revolução Francesa foi abalado com os movimentos sociais do século XIX. A expansão industrial, bem como a formação do operariado urbano, torna acentuado o desenvolvimento social, exigindo-se do Estado uma postura limitadora das antes tão amplas liberdades individuais. Tem-se, com estes fatos, o fundamento para que se superem os direitos do individualismo absoluto e para que surjam os direitos sociais, ou seja, os direitos às "prestações de serviços, cujo obrigado é o Estado: direito ao trabalho, direito à educação, direito à habitação, direito ao seguro social" (VILANOVA, 2003, p. 477). O individualismo e o abstencionismo tornam-se insuficientes, sendo necessária a promoção do bem-estar do maior número possível de pessoas. Está vigente o Estado Social de Direito.

Neste modelo, tendo em vista o acentuado grau de modificação da situação social, a Separação dos Poderes, antes rígida, torna-se flexível. O Estado, para que acompanhe os novos fatos e aponte soluções adequadas e eficientes, não mais pode limitar seu poder a um mecanismo de discussão política nem sempre tão célere, como é a função legislativa. Nas palavras de Vilanova (2003, p. 479), "apenas um órgão de Estado em contato imediato com o fato administrativo está apto a responder a uma realidade social, econômica e política em violenta mutação". Reforça-se, então, o Poder Executivo. A antes tão cuidadosa proteção ao direito individual cede espaço à urgente promoção dos direitos sociais. Revelase forte preocupação com o bem-estar social.

\subsection{Estado Democrático de Direito}

O Estado de Direito, em sua feição liberal, se mostrou insuficiente frente às contingências sociais. O Estado Social trouxe à tona uma nova postura do poder público, havendo novo enfoque em relação à proteção dos direitos individuais, limitando-os à promoção de direitos sociais. O indivíduo é posto em categorias (VILANOVA, 2003, p. 486) segundo a posição que ocupa na sociedade, para uma maior eficácia no controle das recém surgidas questões coletivas. Essa urgência em concretizar o bem-estar faz com que se formem modelos estatais que, nem sempre, têm feições democráticas. Exemplifica-se essa falta de conteúdo democrático com o Estado Social Socialista, regido por ideais de bem-estar coletivo, porém, comandado por um poder ditatorial (SILVA, 2013, p. 114).

Evidenciada a insuficiência do individualismo e o perigo da nãodemocratização do Estado Social, surge a compreensão do Estado Democrático 
de Direito. É um modelo que visa produzir a síntese das conquistas dos outros dois, mas, não somente isso: busca criar uma nova concepção, de modo que superar seus elementos componentes. Nas palavras de José Afonso da Silva (2013, p. 122), este Estado

É um tipo de Estado que tende a realizar a síntese do processo contraditório do mundo contemporâneo, superando o Estado capitalista para configurar um Estado promotor de justiça social que o personalismo e o monismo político das democracias populares sob o influxo do socialismo real não foram capazes de construir.

Esse é o regime adotado pela Constituição Federal de 1988. Durante todo o texto constitucional, verificam-se princípios a ele inerentes e que José Afonso da Silva põe em relevância: o Princípio da Constitucionalidade, segundo qual o Estado se legitima em uma Constituição emanada da vontade popular; o Princípio Democrático, expresso em seu Artigo $1^{\circ}$, que faz com que haja uma democracia representativa e pluralista; o sistema de direitos fundamentais, do qual é conteúdo os direitos individuais, coletivos, sociais e culturais (títulos II, VII e VIII); o princípio da justiça social (Artigo 170, caput); da divisão de poderes (Artigo $2^{\circ}$ ) e da independência do juiz (Artigo 95); da igualdade (Artigo $5^{\circ}$, caput e I); da legalidade (Artigo $5^{\circ}$, II); e da segurança jurídica (Artigo $5^{\circ}$, incisos XXXVI a LXXIII) (SILVA, 2013, p. 124).

\subsection{As Dimensões de Direitos Fundamentais}

Do Estado de Direito ao Social e ao Democrático de Direito, diferentes são os enfoques dos direitos fundamentais. A classificação adotada por boa parte da doutrina nacional (SARLET, 2001) (BONAVIDES, 2013), em dimensões (e não gerações), expõe a convivência entre tais conquistas e leva em conta as experiências e mudanças histórico-sociais do Estado. Nos termos de Sarlet (2001, p. 49), “o uso da expressão 'gerações' pode ensejar a falsa impressão da substituição gradativa de uma geração por outra". Vale dizer: quando dado maior enfoque a uma primeira dimensão, não se exclui a existência da segunda; quando à segunda, a primeira não é inteiramente substituída por esta (não deixa de existir), e assim por diante.

Os direitos de primeira dimensão são aqueles surgidos no momento pósrevolução francesa, em que o indivíduo necessitava firmar suas forças reduzindo 
o campo de atuação do Estado de maneira a criar instrumentos de limitação ao seu poder. São os chamados direitos de liberdade ou, nas palavras de Paulo Bonavides (2013, p. 582), "direitos de resistência ou de oposição perante o Estado", ou, ainda, segundo Sarlet (2001, p. 50), "direitos de defesa”. Cria-se uma "zona de não-intervenção do Estado e uma esfera de autonomia individual em face de seu poder" (SARLET, 2001, p. 50), sendo apresentados como os direitos de caráter negativo, dirigidos a uma "abstenção, e não a uma conduta positiva por parte dos poderes públicos" (SARLET, 2001, p. 50).

No rol desses direitos, citam-se os direitos à vida, liberdade, propriedade e igualdade (formal), bem como as liberdades de expressão, direitos de participação política e algumas garantias processuais, como o devido processo legal e o habeas corpus. Todos estes direitos são visíveis na Constituição Federal de 1988, em seu título II (SARLET, 2001, p. 51).

O crescente número de reivindicações sociais e problemas econômicos que acompanharam o processo de industrialização do século XIX foi acompanhado por uma também crescente força do pensamento socialista e da constatação de que a igualdade e liberdade formais eram insuficientes à efetivação dos direitos do indivíduo. Surgem, então, movimentos que reivindicam direitos de cunho social, exigindo-se do Estado um comportamento ativo. Tratase da segunda dimensão dos direitos fundamentais. São direitos com caráter positivo, que visam, não mais a não interferência estatal, mas sim sua atuação no sentido de concretizá-los da melhor maneira possível, trazendo-se bem-estar social. Nas palavras de Sarlet (2001, p. 51), "não se cuida mais, portanto, de liberdade do e perante o Estado, e sim de liberdade por intermédio do Estado."

Estão no rol desses direitos aqueles que permitem ao indivíduo reivindicar prestações sociais estatais (assistência social, saúde, educação, etc). Para Sarlet, não só se limitam a isso, mas também abrangem as chamadas liberdades sociais, como o direito de greve e de sindicalização. Encontram-se previstos na Constituição de 1988 no título II.

A terceira dimensão encontra-se preponderante a partir do fim do século $\mathrm{XX}$, quando os direitos deixam de se destinar especificamente a um indivíduo, grupo ou Estado, passando a referir-se ao gênero humano. Seu titular é difuso, o que expressa, para Bonavides (2013, p. 588), a afirmação do homem como um "valor supremo em termos de existencialidade concreta". Sarlet (2001, p. 53) explica que estes direitos são, em verdade, "o resultado de novas reivindicações fundamentais do ser humano, geradas, dentre outros fatos, pelo impacto tecnológico, pelo estado crônico de beligerância." 
Destacam-se, entre eles, os direitos à paz (Art. $4^{\circ}$, VI da Constituição de 1988), à autodeterminação dos povos (Art. $4^{\circ}$, III), ao desenvolvimento $\left(\right.$ Art. $3^{\circ}$ ), ao meio ambiente e qualidade de vida (Art. 225), bem como direito à conservação e utilização do patrimônio histórico e cultural (Art.o 216) e o direito de comunicação (Art. 220) (SARLET, 2001, p. 53).

\subsection{A separação dos poderes no estado de direito e estado social}

“Todo poder tende ao abuso". A máxima de Montesquieu ganha relevância extrema no século XVIII, quando o soberano poder do Estado monárquico moderno ameaça o desenvolvimento da economia capitalista. A potência burguesa, antes financiada pelo rei, vê o intervencionismo estatal como um "fantasma que o príncipe em delírio de absolutismo poderia improvisamente soltar" (BONAVIDES, 2011, p. 146), de modo a ser encarado como óbice ao bom progresso da sociedade capitalista recém surgida, mas já consolidada. $\mathrm{O}$ capitalismo demandava, antes de mais nada,

o máximo de liberdade para alcançar o máximo de expansão; demandava portanto menos o paternalismo de um poder obseqüente mas cioso de suas prerrogativas de mando, do que a garantia impessoal da lei, em cuja formação participasse ativa e criadoramente (BONAVIDES, 2011, p. 146).

Torna-se necessário, para que se evite essa interferência do Estado no plano do indivíduo, a formulação de uma teoria política de limitação do poder. Isso toma forma com a clássica obra Do Espírito das Leis, escrita por Montesquieu, em que há a proposta de um modo de organização do soberano poder estatal de forma que o próprio poder limite o poder (Le pouvoir arrête le pouvoir). O princípio da Separação dos Poderes ganha forças com o surgimento da sociedade burguesa e a sua necessidade de resistir ao Estado. É o marco do surgimento do Estado de Direito e da primeira dimensão de direitos fundamentais.

$\mathrm{O}$ pensador francês verifica que toda a atividade estatal resume-se em três funções: a Legislativa, a Executiva e a de Julgar. A essência do pensamento está em separar as funções do Estado em poderes autônomos e independentes, de modo que um fiscaliza o outro, não permitindo que se concentrem em uma única pessoa.

Para que haja harmonia no movimento dos poderes, é necessário um sistema em que eles, mesmo separados, funcionem fiscalizando-se uns aos 
outros. Trata-se do Sistema de Freios e Contrapesos. Assim, sempre que separados, a liberdade estará garantida. Quando reunidos, entretanto, nas mãos de uma só pessoa, ela encontra-se ameaçada: o poder tende à "elaboração de leis tirânicas, sujeitas a uma não menos tirânica aplicação" (BONAVIDES, 2011, p. 151). Fixa-se, assim, um mecanismo de distribuição dos poderes.

Nessa primeira concepção, a Tripartição do Poder auxilia o intento do Estado de tornar o ordenamento algo estático, completo e suficiente, dentro do qual a atividade jurisdicional procuraria toda espécie de solução (VILANOVA, 2003, p. 465). Como se viu, o Estado de Direito tem a atividade legislativa como preponderante. O Judiciário, aqui, é um poder politicamente neutro, com uma função estrita de aplicar a lei já posta (é a boca da lei).

A já apontada mudança social ocorrida à época do grande desenvolvimento industrial dificulta a defesa de um ordenamento estático e a manutenção de uma separação rígida dos poderes. A finalidade do mecanismo torna-se estranha à finalidade do Estado, que deixa de ser a de se abster e não fazer e passa a ser a de concretizar e prestar. Há uma transição no enfoque entre a primeira e a segunda dimensões dos direitos fundamentais. Há uma hipertrofia do Poder Executivo. Como bem escreve Bonavides (2011, p. 157), quando cessada a ameaça da volta do estado ao absolutismo e modificado o enfoque do individual ao social,

cessaram as razões de sustentar, em termos absolutos, um princípio que logicamente paralisava a ação do poder estatal e criara consideráveis contrasensos na vida de instituições que se renovam e não podem conter-se, senão contrafeitas, nos estreitíssimos lindes de uma técnica já obsoleta e ultrapassada.

É possível compreender que o Princípio da Separação dos Poderes acompanha os enfoques dados pelo Estado de Direito e Estado Social às diferentes dimensões de direitos fundamentais.

\subsection{A judicialização da política e a separação dos poderes na constituição de 1988}

A Constituição de 1988 nasceu sob a esperança histórica de ser um documento jurídico com o verdadeiro sentido de normatividade. Ela deixa de ser um documento político, pois contém instrumentos de acesso à justiça, tais 
como a argüição de descumprimento de preceito fundamental, o mandado de injunção e a ação declatória de inconstitucionalidade por omissão, que permitem controle pelo Supremo Tribunal Federal, destacando-o com a atribuição de guardião absoluto da ordem constitucional e democrática (BARROSO, 2013).

A nova ordem constitucional irradia-se por todo o ordenamento jurídico, repercutindo sobre a atuação dos três poderes. Este fenômeno é chamado por Luís Roberto Barroso (2013) de Constitucionalização do Direito.

Nesse quadro, há uma grande aproximação entre o cidadão e a atividade jurisdicional, que passa a exercer significativo papel social e político. Há uma crescente demanda por justiça social, e o Poder Judiciário é o ambiente mais propício a isto. Aqui, é possível apontar outro fenômeno atual que é o da Judicialização das questões políticas e sociais. Neste sentido é possível apontar o fato de o Supremo Tribunal Federal (STF) ter discutido questões como a interrupção da gravidez de feto anencéfalo na Argüição de Descumprimento de Preceito Fundamental (ADPF) $n^{\circ} 54$ e a constitucionalidade das cotas étnicoraciais para seleção de estudantes universitários (ADPF $\left.{ }^{\circ} 186\right)$.

O Judiciário ganhou poder no modelo estatal desenhado pela Constituição de 1988, revelando-se uma diferente dinâmica na tripartição de poderes, hoje não mais absoluta e, cada vez mais, moldada para que as prestações estatais tornem-se suficientes para atender às demandas coletivas. Tem-se o fundamento da judicialização das políticas públicas.

\section{AATIVIDADE JURISDICIONAL E A JUDICIALIZAÇÃO DA POLÍTICA PÚBLICA NO ESTADO DEMOCRÁTICO DE DIREITO}

O papel da jurisdição no contexto do atual Estado brasileiro guarda relações com a evolução dos Estados de Direito e Social. A contribuição do primeiro é, essencialmente, estabelecer limites ao poder estatal, estruturando suas funções de acordo com a clássica idéia da tripartição de poderes de Montesquieu, predominando a função legislativa e dando-se ampla liberdade ao indivíduo. Tem-se, neste momento, a chamada primeira dimensão de direitos fundamentais e um Poder Judiciário neutro (boca da lei), que busca em um ordenamento estático solução aos conflitos que se lhe apresentam. Em razão das mudanças sociais ocorridas a partir da revolução industrial, esse ordenamento torna-se insuficiente, havendo a necessidade de uma nova postura do poder político. 
Essas mudanças trazem consigo o argumento da relativização da interpretação sobre a independência entre os órgãos Legislativo, Executivo e Judiciário e a necessidade de uma atuação mais ampla da função executiva. Vige o Estado Social. Dá-se maior atenção aos direitos sociais (segunda dimensão), que determinam que o Estado deixe de se abster e passe a intervir. A atividade jurisdicional acompanha o ideal de promoção, operando no sentido de atender aos anseios sociais e determinando que se cumpram certos programas constitucionais por parte do Executivo.

O marco da inserção da Força Normativa da Constituição no ordenamento jurídico brasileiro é o que permite a constitucionalização do direito infraconstitucional, que, por sua vez, permite uma maior demanda por justiça social. O Judiciário é o palco adequado para a discussão das demandas, verificando-se na recente jurisprudência pátria grande número de decisões com carga de influência político-social, até mesmo determinando o comportamento dos demais Poderes.

Diante disso, faz-se necessária explicação sobre o modo de organização da atividade jurisdicional em face da Constituição de 1988.

\subsection{As duas atividades da jurisdição}

O quadro exposto permite identificar duas atividades básicas na função jurisdicional brasileira. Uma, que guarda relação com o primeiro momento (direitos de primeira dimensão - solução de conflitos individuais); e outra, que surge com a urgência das demandas por justiça social (APPIO, 2012, p. 64).

Na primeira atividade, o Poder Judiciário atua como um representante estatal, resolvendo conflitos individuais que não afetam as políticas governamentais, sendo dotado de prerrogativas funcionais e limitações estatutárias e portando isenção frente ao caso concreto. É uma atividade que não implica em "interferência direta na atividade dos demais poderes" (APPIO, 2012, p. 65).

Na outra, o Judiciário atua mediante "intervenção direta no espaço tradicionalmente reservado aos demais Poderes", controlando políticas públicas e sendo dotado de independência político-administrativa, permitida devido às garantias previstas no Artigo 96 da Constituição Federal (APPIO, 2012, p. 65). Aqui, percebe-se o fenômeno da Judicialização das Políticas Públicas.

Parte da doutrina identifica, dentro desta segunda vertente, duas figuras distintas, de necessária análise. 


\subsection{A judicialização e o ativismo}

A atividade de interferência na questão social e na política pública é dividida em duas figuras: a da Judicialização e a do Ativismo Judicial.

A Judicialização é uma opção do constituinte em conferir ao Judiciário legitimidade para decidir questões de repercussão político-social que, originariamente, na estrutura tripartite, seriam decididas pelo Congresso Nacional e o Poder Executivo. No fenômeno, a vontade não é do judiciário. Nas palavras de Barroso: "A judicialização, que de fato existe, não decorreu de uma opção ideológica, filosófica ou metodológica da Corte. Limitou-se ela a cumprir, de modo estrito, o seu papel constitucional, em conformidade com o desenho institucional vigente" (BARROSO, 2013). Ele atua quando provocado e não tem outra opção senão se manifestar acerca das ações a ele submetidas.

O Ativismo, por sua vez, é a postura participativa do Judiciário na concretização de valores e fins constitucionais. É atitude oposta à da autocontenção judicial, em que o Judiciário evita a aplicação direta da Constituição, aguardando o pronunciamento do legislador ordinário e se abstém de interferir na definição das políticas públicas (BARROSO, 2013).

Verifica-se a principal diferença entre as figuras: enquanto a Judicialização consiste em uma opção do constituinte, que determina um comportamento inevitável do Poder Judiciário, o Ativismo é a sua postura (como o próprio termo já acusa) ativa, no sentido de dar uma alternativa à inércia e ineficiência do processo político tradicional. Apesar de distintas, ambas são figuras que caminham juntas, podendo-se até mesmo afirmar que a opção pela Judicialização dá espaço para a postura de Ativismo.

Barroso percebe questionamentos sistemáticos a esta atuação do Judiciário. Diz-se que há problemas como a legitimidade democrática do Judiciário, a politização da justiça e a falta de capacidade institucional do Judiciário para decidir determinadas matérias.

A legitimidade democrática do Judiciário é questionada, vez que os magistrados não são agentes públicos eleitos. Mesmo assim, têm, como já visto, papel político intenso. A justificativa para isso, diz Barroso (2013), é dada, sob um ponto de vista normativo, pelo simples fato de que "a Constituição brasileira atribui expressamente esse poder ao Judiciário." Vale dizer: não há a aplicação, na atividade em destaque, da vontade política do próprio juiz, mas sim da Constituição. Já sob um ponto de vista filosófico, justifica-se devido ao fato de que o Estado constitucional é produto de uma constituição elaborada pela 
soberania popular e, assim, ao dar ao magistrado uma função coerente com seus objetivos, dá também uma função protetiva ao ideal de democracia. "A jurisdição constitucional bem exercida é antes uma garantia para a democracia do que um risco" (BARROSO, 2013).

A politização da justiça seria um desvirtuamento da noção da judicialização da política. Seria tornar o argumento político um argumento jurídico. Barroso (2013) traz a seguinte reflexão: direito é política, no sentido de que

A Constituição faz a interface entre o universo político e o jurídico, em um esforço para submeter o poder às categorias que mobilizam o Direito, como a justiça, a segurança e o bem-estar social. Sua interpretação, portanto, sempre terá uma dimensão política, ainda que balizada pelas possibilidades e limites oferecidos pelo ordenamento vigente.

E, ao mesmo tempo, não é política, visto que não admite "escolhas livres, tendenciosas ou partidarizadas": o juiz não pode ser faccionista. A decisão judicial não comporta discricionariedade política plena, estando vinculada ao "dever de motivação, mediante o emprego de argumentação racional e persuasiva" (BARROSO, 2013).

Por fim, aponta-se o questionamento quanto à capacidade institucional do Poder Judiciário. Aqui, duas idéias são exploradas: a da própria capacidade institucional e a dos efeitos sistêmicos das decisões judiciais.

A capacidade institucional envolve "a determinação de qual Poder está mais habilitado a produzir a melhor decisão em determinada matéria" (BARROSO, 2013). Conforme observa Appio, a governabilidade do Brasil tem por influência a atividade jurisdicional, visto que suas decisões têm a "capacidade de controlar, de algum modo, as demais forças políticas" (APPIO, 2012, p. 70). Mesmo assim, nem sempre é possível dizer que o Judiciário terá a maior aptidão técnica para decidir da melhor maneira na questão que lhe é submetida, o que faz com que ele deva "prestigiar as manifestações do Legislativo ou do Executivo, cedendo o passo para juízos discricionários dotados de razoabilidade" (BARROSO, 2013).

Quanto aos efeitos sistêmicos, diz-se que o juiz, "por vocação e treinamento, estará preparado para realizar a justiça do caso concreto, a microjustiça", não dispondo de tudo o que necessário para avaliar corretamente o impacto de algumas de suas decisões. Isto se ilustra com o exemplo da judicialização da saúde (BARROSO, 2013). 
Os questionamentos permitem observar que há limites à hodierna atuação do Poder Judiciário.

\section{OS LIMITES À JUDICIALIZAÇÃO DA POLÍTICA PÚBLICA}

A principal sistematização dos limites à Judicialização da Política Pública é feita por Ada Pellegrini Grinover que, ao analisar a decisão monocrática proferida pelo Ministro Celso de Mello na Argüição de Descumprimento de Preceito Fundamental de $n^{\circ} 45$, aponta como três os principais pontos a serem postos em ponderação na intervenção judicial. A saber:

(1) o limite fixado pelo mínimo existencial a ser garantido ao cidadão; (2) a razoabilidade da pretensão individual/social deduzida em face do Poder Público e (3) a existência de disponibilidade financeira do Estado para tornar efetivas as prestações positivas dele reclamadas (GRINOVER, 2009, p. 42).

O mínimo existencial consiste no núcleo central dos direitos que conferem ao homem condições de vida digna. No rol destes direitos, costuma-se incluir os direitos à educação fundamental, saúde básica, saneamento básico, assistência social, tutela do ambiente e acesso à justiça (GRINOVER, 2009, p. 43). Para que este núcleo essencial venha a ser efetivado, o Judiciário, no plano da demanda que a ele se submete, se utilizará de critérios como a razoabilidade e a proporcionalidade.

A razoabilidade é medida pela aplicação do princípio da proporcionalidade que, por sua vez, em sentido amplo, significa "a busca do justo equilíbrio entre os meios empregados e os fins a serem alcançados" (GRINOVER, 2009, p. 43). Traduz-se em três subprincípios: o da conformidade ou adequação de meios, o da exigibilidade ou necessidade e o da proporcionalidade em sentido estrito. O primeiro, "impõe que a medida seja adequada ao fim"; o segundo, que "haja a menor desvantagem possível ao cidadão"; e o último, por sua vez, que haja a "justa medida entre os meios e o fim". Nas palavras de Grinover (2009),

a intervenção judicial nas políticas públicas só poderá ocorrer em situações em que ficar demonstrada a irrazoabilidade do ato discricionário praticado pelo poder público, devendo o juiz pautar sua análise em atenção ao princípio da proporcionalidade. 
A teoria da reserva do possível traz à tona a idéia de que, para a implementação dos direitos sociais, são necessárias políticas públicas que exigem recursos públicos financeiros de montante considerável. São direitos de custo elevado e que, ao momento da efetivação dos direitos de segunda dimensão, exigirão, por parte do juiz, a reflexão sobre os desdobramentos econômicos de sua decisão. Aqui, gira importante debate quanto à contraposição entre a urgente necessidade de concretização do mínimo existencial e a disponibilidade financeira de recursos públicos. Põe-se, de um lado, a igualdade material, escopo fundamental do ordenamento posto pela Constituição de 1988; e, de outro, a escassez de verbas para a consecução deste objetivo (SARLET; FIGUEIREDO, 2008, p. 179-234).

Seguindo a linha de raciocínio da autora, Luís Francisco Aguilar Cortez (2013, p. 290) faz acurada análise dos três vetores básicos, descrevendo os limites à Judicialização com três outras expressões. Defende que existem limites fáticos, políticos e jurídicos, os quais auxiliam a compreensão do fenômeno.

\subsection{Limites fáticos}

Os limites fáticos, na classificação de Cortez (2013, p. 290) são os limites relativos à disponibilidade de recursos, critérios e fases de alocação e trata-os sob os títulos de: i) recursos disponíveis e princípio da eficiência; e, ii) planejamento econômico, planos de ação e exeqüibilidade das decisões.

Quanto ao primeiro aspecto, Cortez trata da reserva do possível, estabelecendo relação com o princípio da eficiência. A reserva do possível condiciona a efetivação de determinados direitos à disponibilidade financeira do Estado; a eficiência determina que se busque o melhor desempenho possível, devendo a administração se organizar também desta forma (2013, p. 290). Neste sentido, há um "limite técnico" para a Judicialização de políticas públicas. Vale dizer: na delicadeza da situação de escassez de verba, é necessário que se faça o melhor com o que se tem, e nem sempre o Poder Judiciário terá o aparelhamento técnico para a tomada dessa decisão (da decisão mais eficiente). Nem sempre o juiz estará tão preparado como a Administração para que escolha da utilização dos recursos públicos disponíveis. Isto exige cuidado do Judiciário na apreciação das demandas que lhe são submetidas. É limite relacionado com a capacidade institucional do Judiciário.

Quanto ao segundo aspecto, aponta Cortez (2013, p. 293) que há vezes em que os representantes eleitos não dão a devida atenção ao planejamento de ações estatais. Isto faz com que a intervenção judicial em políticas públicas 
ganhe força: o descaso quanto aos direitos sociais dependentes deste planejamento faz com que reste apenas a via judicial para sua concretização.

Em face de tais constatações, aponta dois problemas: i) diante da existência de programas de ação específicos para determinada área, “a possibilidade de intervenção jurisdicional relativa às escolhas exercidas fica evidentemente reduzida" (2013, p. 293), visto que uma vez desenvolvida a formulação de políticas pelos poderes competentes, limita-se a atuação judicial. A exceção a esta regra reside no caso em que o planejamento ou programa não protege efetivamente o direito que se busca, bem como naquele em que há a necessidade de reavaliações em situações emergenciais; ii) caso "estabelecidas metas e destinados recursos, tais atos estarão sujeitos ao controle judicial" (2013, p. 294). Há, entretanto, problema, quando relacionado o orçamento participativo com a intervenção jurisdicional: o maior grau de participação política, contraposto à decisão judicial pode trazer questionamentos quanto à própria legitimidade democrática da intervenção. Em suma: havendo planejamento, o Judiciário não atuará, salvo se não cumprido, se a proteção conferida for inferior à necessária ou em casos de urgência; além disso, sua atuação se limita conforme for o nível de participação social na elaboração do orçamento.

Por fim, alerta que "decisões judiciais não podem alterar, de imediato, as condições reais existentes" (CORTEZ, 2013, p. 290). Explica:

Mesmo diante de eventual omissão dos demais Poderes, são inócuas determinações que desconsiderem o que efetivamente pode ser realizado em relação ao problema apresentado; decisões judiciais inexeqüíveis apenas desacreditam a função jurisdicional (CORTEZ, 2013, p. 290).

Nos termos apresentados defende-se que o juiz deve ter a sensibilidade para não extrapolar o limite fático da falta de recursos, sob pena de colocar em risco confiança em sua importante função de controlador de políticas públicas. A decisão inexequiível enfraquece o Poder Judiciário.

\subsection{Limites políticos}

No aspecto dos limites políticos considera $\operatorname{Cortez}(2013$, p. 293) a atuação do Judiciário em seu quadro de atribuições e funções, ou seja: i) separação dos poderes e governabilidade; e, ii) responsabilidade política e social dos magistrados. 
A independência dos poderes e governabilidade são discursos comuns da Administração em ações que questionam a efetivação de direitos sociais. No entanto, contrapõem-se a este argumento a necessidade de efetividade dos direitos sociais. Portanto, o princípio da tripartição torna-se menos rígido, permitindo a judicialização.

Devido ao fato de que as funções Legislativa e Executiva têm mais proximidade da vontade popular, a formulação das políticas públicas é própria, em princípio, ao exercício de suas atribuições, e não das do Judiciário, cumprindo a este somente zelar pelo seu cumprimento e execução (CORTEZ, 2013, p. 295). Assim, o Judiciário deve adotar postura de auto-contenção em determinadas situações, para que haja "aplicação harmônica dos princípios constitucionais" (CORTEZ, 2013, p. 296).

São noções que se aproximam da noção de governabilidade: o Judiciário deve respeitar a distribuição de atribuições quando as decisões dos demais Poderes forem respostas mais adequadas às demandas sociais.

Quanto à responsabilidade política e social dos magistrados, sob o aspecto funcional, não respondem politicamente ao exercer a atividade jurisdicional. Sob o aspecto institucional, entretanto, diz Cortez (2013, p. 297) que, "considerada a diversidade de matérias submetidas à sua apreciação, evidente que o Direito, seus interpretes e aplicadores cumprem função política, com os correspondentes reflexos sociais". Isto quer dizer que, ao aplicar o direito, há necessária reflexão do magistrado acerca do contexto social, não se restringindo apenas à análise formal da situação. Assim, sua atividade deve levar em conta os limites institucionais do Judiciário em face das competências das demais instituições.

\subsection{Limites jurídicos}

Quanto aos limites jurídicos, é importante destacar os seguintes aspectos apresentados por Cortez (2013, p. 297): i) direitos sociais prestacionais; ii) princípios da impessoalidade e isonomia; iii) omissão legislativa e leis regulamentadoras; e, iv) legitimação, motivação e coerência

O primeiro aspecto de relevante atenção é importante para apontar que o fato de os direitos fundamentais sociais, por serem prestacionais, fazem com que haja certa relação de sua aplicabilidade (eficácia jurídica) com sua eficácia social (efetividade). A aplicabilidade da norma de direito social é fator que deve ser levado em conta na discussão de sua efetividade. A valoração jurídica dos direitos envolvidos nas ações que os discutem deve 
complementar a avaliação jurisdicional dos limites como a reserva do possível (CORTEZ, 2013, p. 300).

Quanto ao segundo aspecto, argumenta-se que os princípios da impessoalidade e da isonomia impedem o atendimento às pretensões relativas a direitos sociais. Isto, com base no fato de que atendimentos individualizados, "diante do caráter universal das prestações sociais e restrições econômicas à sua implantação, caracterizariam tratamento diferenciado vedado pela Constituição" (CORTEZ, 2013, p. 301). É entendimento expressado pela máxima: se não posso atender igualmente a todos, não atendo a ninguém. Cortez (2013, p. 301) critica severamente essa linha de argumentação, tendo em vista que isso inviabilizaria a prestação de direitos sociais reconhecidos como direitos subjetivos.

No terceiro aspecto, relativo à omissão legislativa e leis regulamentadoras, constata-se que Constituição Federal de 1988 elenca grande rol de direitos, sem se preocupar com os meios necessários para que venham a ser concretizados - isso é alvo de críticas. Esses direitos precisam de instrumentos para sua efetivação. Caso os poderes Legislativo e Executivo se omitam quanto ao que determina a Constituição, a atuação do Judiciário torna-se mais justificada, permitindo-se que ele venha a impedir que esses direitos sejam abandonados. Obedecidos os demais limites, o Judiciário poderá atuar no sentido de estabelecer obrigações relativas a estas políticas públicas sobre as quais as demais funções são inertes (CORTEZ, 2013, p. 302). O Judiciário tem, aqui, uma função importante: a de garantir o mínimo de efetividade aos direitos de regulamentação inexistente ou obscura. Em situações de omissão, há ambiente propício para o exercício da função judiciária de controle e implementação de políticas públicas.

No que diz respeito ao último aspecto, tendo em vista que as decisões relativas às políticas públicas têm encargo político e social elevado, influindo até mesmo na atribuição dos demais Poderes, é exigida uma motivação e coerência diferenciada. Aqui, não basta o dever de fundamentação das decisões. Há, também, a necessidade de confirmar a legitimidade da jurisdição em sua atividade. Surge o que Cortez (2013, p. 304) chama de "motivação qualificada".

Exploradas todas essas questões que nos permitem entender o papel do Poder Judiciário no Estado Democrático de Direito, que acompanha o ideal de promoção dos direitos de segunda dimensão, torna-se necessária a compreensão dos contornos jurídicos da norma constitucional que tanta dificuldade encontra de concretização. É necessário o estudo da classificação dessa norma quanto à sua eficácia e aplicabilidade. 


\section{A CLASSIFICAÇÃO DA NORMA CONSTITUCIONAL DE DIREITO FUNDAMENTAL SOCIAL DE ACORDO COM SUA EFICÁCIA E APLICABILIDADE}

A norma jurídica, para merecer operatividade em um sistema jurídico, deve ser aplicável e eficaz. Esta eficácia, sob um ponto de vista jurídico, é a qualidade de produzir efeitos jurídicos; do social, a de determinar condutas. Só se fala em efetividade (eficácia social) quando se sabe da eficácia jurídica de uma norma.

A principal obra na doutrina nacional que trata da classificação da aplicabilidade e eficácia das normas constitucionais é a de José Afonso da Silva, intitulada Aplicabilidade das Normas Constitucionais.

$\mathrm{O}$ autor interpreta a doutrina italiana e traz influente classificação das normas quanto à eficácia e aplicabilidade. Partindo da premissa de que as normas de direito constitucional são dotadas, todas, de um mínimo de eficácia, classificaas em (a) De eficácia plena e aplicabilidade direta, imediata e integral, que são aquelas que produzem ou têm a possibilidade de produzir todos os seus efeitos nucleares desde a entrada em vigor da Constituição, incidindo direta e imediatamente sobre a matéria que é seu objeto, não exigindo qualquer elemento para sua executoriedade, nem comportando restrições; (b) De eficácia contida e aplicabilidade direta, imediata, mas possivelmente não integral, que são as que prevêem meios que permitem manter sua eficácia em certos limites em determinadas circunstâncias - são aplicáveis desde já, mas comportam restrições infraconstitucionais; (c) De eficácia limitada, que não produzem todos os seus efeitos essenciais desde a entrada em vigor, exigindo-se normatividade infraconstitucional que complemente a de nível constitucional. (SILVA, 1982, p. 73).

A classificação tem o mérito de mostrar que as normas constitucionais têm sua aplicabilidade variada conforme a necessidade ou não de normatividade de plano infraconstitucional.

As normas de direito fundamental social são próprias à categoria das de eficácia limitada, uma vez que traçam princípios a serem cumpridos na realização dos fins sociais do Estado (fins de realização da justiça social). São normas de eficácia limitada declaratórias de princípios programáticos.

A clássica doutrina de José Afonso encontra complementação na obra de Celso Antônio Bandeira de Mello, Eficácia das Normas Constitucionais e Direitos Sociais (2009), em que se expõe certa insuficiência daquela e propõe- 
se novo estudo; desta vez, sob um ponto de vista distinto: o fato de a norma constitucional conferir ou não a um administrado posição jurídica de titular de direito exigível em face da administração.

Esta constatação de Celso Antônio Bandeira de Mello parte da noção de que, apesar de muitas vezes as normas de eficácia plena conferirem posição jurídica forte, em outras inúmeras situações "são, precisamente, as que conferem a posição mais débil para os administrados" (MELLO, 2009, p. 19).

A classificação sugerida pelo segundo autor é a seguinte: (a) Normas de Outorga de Poder Jurídico, que não impõem uma obrigação a ser solvida por outrem, conferindo ao sujeito do poder, sem concurso de qualquer pessoa, a fruição imediata do bem jurídico - não requerem uma atuação, mas sim uma abstenção do Poder Público; (b) Normas de Direito em Sentido Estrito, cuja fruição do bem jurídico depende de prestação alheia, realizando-se dentro de uma relação jurídica e concretizando-se com o cumprimento da obrigação que a compõe - é algo semelhante com um direito subjetivo; (c) Normas de Expressão de Finalidade a ser cumprida pelo Poder Público, que são as que não indicam as condutas específicas que satisfariam o bem jurídico consagrado na regra - não indicam os meios para o cumprimento da finalidade, conferindo posição jurídica dos administrados de menor consistência. (MELLO, 2009, p. 22-24)

Os dois primeiros grupos comportam uma subdivisão em normas (i) insuscetíveis de restrição, como é o caso do direito ao salário mínimo, previsto no Artigo $7^{\circ}$, VII CF/88: o salário nunca será inferior ao mínimo, não permitindose que se abra espaço para que a lei restrinja o direito; (ii) restringíveis por lei ordinária, como é o caso do Direito de Greve, que se dará na forma da lei, conforme discrimina o Artigo 37, VII CF/88; (iii) delimitadoras com exatidão do conteúdo do direito, que se utilizam de "expressões inelásticas" - de significado preciso, como é o caso do Artigo $7^{\circ}, \mathrm{XV} \mathrm{CF} / 88$, que assegura ao trabalhador o direito ao descanso semanal remunerado; (iv) delimitadoras por aproximação do conteúdo do direito, cujas expressões são "elásticas" - de "significado fluido", como a proibição ao trabalho noturno perigoso ou insalubre aos menores de 18 anos (MELLO, 2009, p. 25-27).

Estas classificações do segundo autor permitem entender que a Constituição, ao prever as normas de direito fundamental social, confere aos administrados posição de exigibilidade em face do poder público para que se concretizem determinadas prestações de cunho social, visando, assim, que se cumpram os ideais de Justiça Social do Estado Social. Isto é: há 
inconstitucionalidade na ação do Estado que não atenda a estes ideais, bem como na omissão.

Percebe-se o grande grau de eficácia jurídica das normas de direito social. As normas de direitos fundamentais sociais são aplicáveis de um ponto de vista da eficácia jurídica; há, entretanto, um problema na eficácia social. Esse problema de efetividade ficará demonstrado no exemplo da saúde, que se segue.

\section{PROBLEMAS NA EFETIVIDADE DOS DIREITOS FUNDAMENTAIS SOCIAIS}

Os direitos fundamentais sociais inserem-se na segunda dimensão dos direitos fundamentais e, apesar de também possuírem uma face negativa que impõe dever de abstenção ao Estado, como ocorre no direito à Moradia, no qual, ao mesmo tempo em que pode-se bloquear o acesso de qualquer um a ela, é possível que se requeira que o Estado dê acesso a ela (SARLET; FIGUEIREDO, 2008, p. 179-234) -, se caracterizam, especialmente, por conferirem às pessoas o direito de exigir do Poder Público prestações que tenham por escopo a concretização da Justiça Social. É objetivo da República Federativa do Brasil promover o bem de todos (Artigo $3^{\circ}, \mathrm{CF} / 88$ ). Pode-se, assim, exigir do Estado que preste, por exemplo, Educação, Transporte e Saúde, construindo escolas, viabilizando transporte público e construindo hospitais, fornecendo medicamentos, etc.

O principal problema que se verifica na implementação destas prestações de direitos sociais é de caráter econômico. A promoção da igualdade material pelo Estado exige que sejam despendidas enormes quantidades de recursos públicos, nem sempre sendo possível que seja tudo entregue conforme desejado pelo constituinte. Reconhece-se o caráter de direito fundamental a estes direitos, ressaltando-se o fato de que "as normas constitucionais são comandos normativos e não peças de literatura" (SILVEIRA, 2009, p. 169); entretanto, a atuação estatal condiciona-se a certos limites: "o Direito não tem o condão de gerar recursos materiais por decreto nem de alterar por portaria o nível de desenvolvimento econômico, social e cultural de um país" (SILVEIRA, 2009, p. 172).

Bom exemplo a se dar é o do Direito à Saúde. É dever do Estado e direito subjetivo da população exigir dele a concretização de sua saúde. Sendo assim, o direito à saúde é algo que pode ser levado ao Judiciário. 
Há, hoje, ajuizamento em massa de demandas que buscam, com base na garantia constitucional à prestação de saúde, que o Estado dê acesso a medicamentos e procedimentos médicos pelo Sistema Único de Saúde.

Conforme aponta artigo escrito por Gisele Chaves Sampaio Alcântara (2012, p. 88-94), metade de todo o orçamento destinado à saúde no Estado do Rio Grande do Sul é consumido no cumprimento de decisões judiciais, cujo montante saltou de R \$ 9 milhões em 2005 para R 22 milhões em 2006; além disso, em âmbito federal, de janeiro a julho de 2008, o Governo gastou diretamente $\mathrm{R}$ \$ 48 milhões com ações judiciais para a aquisição de medicamentos. Em três anos, o aumento chegou a $1.920 \%$, quando considerado que, em 2006, o gasto foi de $\mathrm{R} \$ 2,5$ milhões de reais; por fim, aponta que, em notícia veiculada pelo jornal $O$ Estado de São Paulo, foi mostrado que os valores gastos pelo Ministério da Saúde para cumprir decisões judiciais que determinavam o fornecimento de medicamentos de alto custo aumentaram mais de $5.000 \%$ de 2005 a 2010 foram gastos $\mathrm{R} \$ 2,24$ milhões em 2005 contra $\mathrm{R} \$ 132,58$ milhões em 2010.

$\mathrm{Se}$, de um lado, reconhece-se que o direito à saúde, assim como todos os outros direitos fundamentais sociais, compõe um mínimo existencial, ou seja, um mínimo sem o qual é impossível a qualquer pessoa que viva com dignidade, reconhece-se também que a verba disponível ao Poder Público para que o concretize é limitada, sendo possível que se diga que há uma limitação fática à efetividade das normas constitucionais de direito social - há que se falar em uma reserva do possível.

O Judiciário, neste âmbito de judicialização de políticas públicas também não pode escusar-se de sua responsabilidade social ao determinar que o direito seja efetivado sem que busque entender os reflexos econômicos de suas decisões. Este será o cerne de toda questão colocada em juízo envolvendo direitos sociais: a escassez de recursos, a condição de realidade colocada em balança com um núcleo essencial de direitos de necessária concretização.

Percebe-se, assim, o problema existente na concretude do direito social. Trata-se de um problema que contém a questão dos limites econômicos à prestação positiva estatal.

\section{CONSIDERAÇÕES FINAIS}

O Estado Democrático de Direito que a $\mathrm{CF} / 88$ visa construir tem por fundamento noções próprias ao Estado de Direito liberal e ao Estado Social. No momento atual há preocupação da busca de efetividade aos direitos sociais, 
de segunda dimensão, que forçam uma atuação estatal voltada a prestações de caráter positivo. Diante deste desafio a jurisdição se aproxima do povo e o Poder Judiciário ganha peso, influindo em questões político-sociais de alta relevância. Tem-se, com isso, o fundamento de outro fenômeno: o da judicialização das políticas públicas.

A jurisdição, nesses moldes traçados pelo Estado Democrático de Direito, exerce duas atividades básicas: (i) de solução de conflitos - função clássica; (ii) de interferência nas decisões políticas dos demais poderes - função de controle judicial das políticas públicas (Judicialização). A noção de que o Poder Judiciário atua desta segunda forma traz algumas reflexões, que apontam certos limites à Judicialização. A principal sistematização mostrada foi a de Ada Pellegrini Grinover, elaborada em análise da jurisprudência do STF (Arguição de Descumprimento de Preceito Fundamental ${ }^{\circ} 45$ ). Diz ela que a ponderação nas ações que discutem a concretização dos direitos fundamentais de segunda dimensão deve envolver três vetores básicos, que são o mínimo existencial, a razoabilidade e proporcionalidade, e a reserva do possível.

É clara a existência, fundamento e os principais limites que envolvem o fenômeno da judicialização. Percebe-se, também, que entre esses limites está uma ponderação de valores que permite questionar os motivos da inefetividade das normas de direito fundamental social, fazendo com que sejam necessárias noções sobre a eficácia e aplicabilidade das normas constitucionais.

Esta eficácia pode ser vista sob ponto de vista jurídico e, ainda, social. Do ponto de vista jurídico, a norma é eficaz sempre que possuir qualidade de produzir efeitos jurídicos; do social, ao determinar condutas. Só se fala em efetividade (eficácia social) quando se sabe da eficácia jurídica de uma norma. Os direitos fundamentais sociais são direitos inseridos no ordenamento por normas constitucionais de eficácia limitada declaratória de princípios programáticos, na clássica sistematização de José Afonso da Silva. Essa classificação é incompleta para os fins do presente trabalho: o desenvolvimento da noção de que a norma é capaz de gerar direito exigível e, portanto, plenamente efetivável. Aponta-se, assim, outra classificação, que é a de Celso Antônio Bandeira de Mello, segundo a qual as normas de direitos fundamentais sociais conferem aos administrados posição de exigibilidade em face do poder público, sob pena de ser cometida grave inconstitucionalidade.

A norma de direito fundamental social tem forte carga de eficácia jurídica, ao ponto de ser possível afirmar que a desobediência aos seus comandos caracteriza verdadeira inconstitucionalidade e uma grave irresponsabilidade 
governamental. Sua mera inobservância sem motivação adequada não é aceitável.

Diante disso tudo, defende-se que o argumento que pode levar ao problema da inefetividade da norma de direito fundamental social a um patamar de discussão razoável é a dura condição de realidade enfrentada pela administração: a escassez de recursos. Ou seja, é um problema sóciofinanceiro, e não jurídico, e passa pela ponderação entre a Reserva do Possível e o Mínimo Existencial.

\section{REFERÊNCIAS}

ALCÂNTARA, Gisele Chaves Sampaio. Judicialização da Saúde: uma reflexão à luz da teoria dos jogos. Revista CEJ. Brasília, n, 57, p. 88-94, maio./ago. 2012.

APPIO, Eduardo. Controle Judicial das Políticas Públicas no Brasil. 1. ed. Curitiba: Juruá, 2012. 304 p.

BARROSO, Luís Roberto. Neoconstitucionalismo: O triunfo tardio do Direito Constitucional no Brasil. Disponível em: <http:// conjur.estadao.com.br//static/text/43852,12 >. Acesso em: 26 ago: 2013.

BARROSO, Luís Roberto. Judicialização, Ativismo Judicial e Legitimidade Democrática. Disponível em: <http://www.oab.org.br/ editora/revista/users/revista/1235066670174218181901.pdf >. Acesso em: 03 set. 2013.

BONAVIDES, Paulo. Ciência política. 18. ed. São Paulo: Malheiros, 2011. $550 \mathrm{p}$.

BONAVIDES, Paulo. Curso de direito constitucional. 28. ed., atual. São Paulo: Malheiros, 2013. 864 p.

CORTEZ, Luís Francisco Aguilar. Outros limites ao controle jurisdicional de políticas públicas. In: GRINOVER, Ada Pellegrini; WATANABE, Kazuo. O Controle Jurisdicional de Políticas Públicas. 2 ed. Rio de Janeiro: Forense, 2013. p. 285-307. 
GRINOVER, Ada Pellegrini. O processo: estudos e pareceres. 2. ed. São Paulo: DPJ Editora, 2009. 880 p.

MELLO, Celso Antônio Bandeira de. Eficácia das normas constitucionais e direitos sociais. 1. ed. São Paulo: Malheiros, 2009. 62 p.

SARLET, Ingo Wolfgang. A eficácia dos direitos fundamentais. 2. ed. rev. e atual. Porto Alegre: Livraria do Advogado, 2001. 392 p.

SARLET, Ingo Wolfgang; FIGUEIREDO, Mariana Filchtiner. Reserva do possível, mínimo existencial e direito à saúde: algumas aproximações. Revista da Defensoria Pública. São Paulo, n. 1, p. 179-234, jul./dez. 2008.

SILVA, José Afonso da. Aplicabilidade das normas constitucionais. 2 ed., rev. e atual. São Paulo: Revista dos Tribunais, 1982. 258 p.

SILVA, José Afonso da. Curso de direito constitucional positivo. 36 . ed. São Paulo: Malheiros, 2013. 928 p.

SILVEIRA, Paulo Antônio Caliendo Velloso da. Direito tributário e análise econômica do direito: uma visão crítica. Rio de Janeiro: Elsevier, 2009. xxiii, 369 p.

VILANOVA, Lourival. Escritos Jurídicos e Filosóficos, v. 2. São Paulo: Axis Mundi: IBET, 2003. 498 p.

Artigo recebido em: 08/10/2014 Aprovado para publicação em: 21/11/2014

Como citar: KEMPFER, Marlene. MORAES, Rafael Zambon de. Judicialização das políticas públicas e inefetividade dos direitos sociais na Constituição Federal de 1988. Revista do Direito Público. Londrina, v.9, n.3, p.71-96, set./dez.2014. DOI: 10.5433/1980-511X.2014v9n3p71. 